Article

\title{
Antioxidant Activity and Proanthocyanidin Profile of Selliguea feei Rhizomes
}

\author{
Caili Fu ${ }^{1}$, Hongyu Wang ${ }^{2}$, Wei Ling $\mathrm{Ng}^{2}$, Lixia Song ${ }^{2}$ and Dejian Huang ${ }^{2}{ }^{2}$ \\ 1 College of Bioscience \& Biotechnology, Fuzhou University, Fuzhou 350108, Fujian, China \\ 2 Department of Chemistry, National University of Singapore, 3 Science Dr. 3, \\ Singapore 117543, Singapore
}

* Author to whom correspondence should be addressed; E-Mail: chmhdj@nus.edu.sg; Tel.: +65-6516-8821; Fax: +65-6775-7895.

Received: 20 March 2013; in revised form: 4 April 2013 / Accepted: 8 April 2013 /

Published: 11 April 2013

\begin{abstract}
Proanthocyanidins from the rhizomes of Selliguea feei (PSFs) were solvent-extracted and fractionated by Sephadex LH-20 column chromatography to give a $2.42 \%$ isolated yield (dry matter basis). ${ }^{1} \mathrm{H}-\mathrm{NMR}$ spectroscopy revealed the mean degree of polymerization (mDP) to be 2.6. ${ }^{13} \mathrm{C}-\mathrm{NMR}$ analysis showed typical signals for afzelechin/epiafzelechin units. Clear peaks at $76 \mathrm{ppm}$ and $84 \mathrm{ppm}$ indicated that both stereoisomers (afzelechin/epiafzelechin) are present. In agreement with the NMR spectra, the ESI-MS spectrum indicated that PSFs are mainly monomers to trimers consisting of afzelechin/epiafzelechin units with A-type and B-type interflavanyl linkages. A trimer was purified and identified as demethylated selligueain B. Thiolysis confirmed the structure and the thiolytic products, methyl 2-[(2R, 3R, 4S)-3,5,7-trihydroxy-2-(4-hydroxyphenyl)chroman4-yl]acetate (1) and 4 4 -(carboxymethyl)sulphanylepiafzelechin- $(2 \beta \rightarrow \mathrm{O} \rightarrow 7,4 \beta \rightarrow 8)$ epiafzelechin methyl ester (2), were purified and characterized. Selligueain A, demethylated selligueain B, compounds $\mathbf{1}$ and $\mathbf{2}$ possess high antioxidant capacity at $1.18 \times 10^{4}, 1.16 \times 10^{4}, 0.95 \times 10^{4}$ and $1.29 \times 10^{4} \mu \mathrm{mol} \mathrm{TE} / \mathrm{g}$, respectively.
\end{abstract}

Keywords: Selliguea feei; proanthocyanidins; thiolysis; antioxidant activity 


\section{Introduction}

Selliguea feei is a species of edible fern belonging to the Polypodiaceae family. It is a perennial plant that inhabits the forests of Indonesia and Philippines. In western Java, tea made from the rhizomes of $S$. feei is traditionally used as a male tonic. An A-type propelargonidin trimer, selligueain A (Figure 1) was isolated from the rhizomes of S. feei and shown to be nontoxic in preliminary acute toxicity tests in mice [1]. In addition, it was reported that selligueain A possesses anti-inflammatory

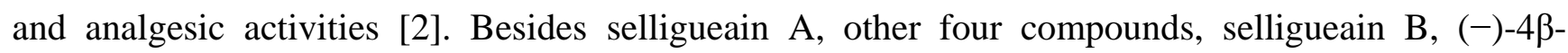
carboxymethyl epiafzelechin, (+)-afzelechin-O- $\beta-4$ '-D-glucopyranoside (Figure 1) and kaempferol-3O- $\beta$-D-glucopyranoside-7-O- $\alpha$-L-rhamnopyranoside, were also isolated from this plant [3]. However, the proanthocyanidin profile of the rhizomes of S. feei (PSFs) is not clear.

Figure 1. Flavanol monomers and proanthocyanidins reported in Selliguea feei.<smiles>O=C(O)C[C@H]1c2c(O)cc(O)cc2O[C@H](c2ccc(O)cc2)[C@H]1O</smiles>

(-)- 4ß-carboxymethyl epiafzelechin

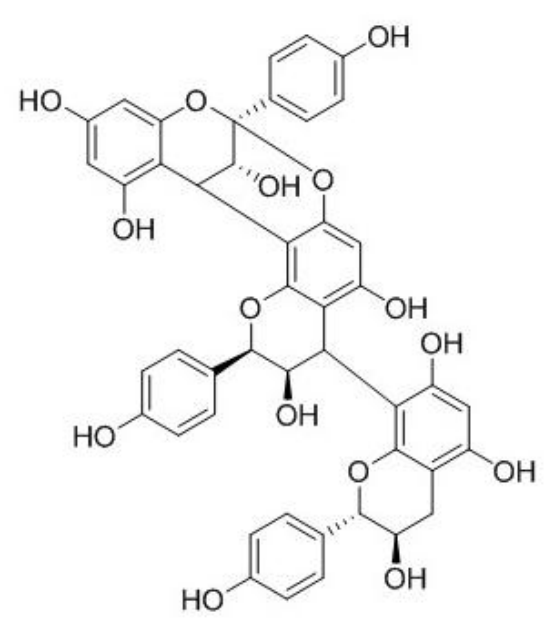

Selligueain A<smiles>Oc1cc(O)c2c(c1)O[C@H](c1ccc(OC3OC4C(O)OC(C3O)C4O)cc1)[C@H](O)C2</smiles>

(+)-afzelechin-O- $\beta-4$ '-D- glucopyranoside

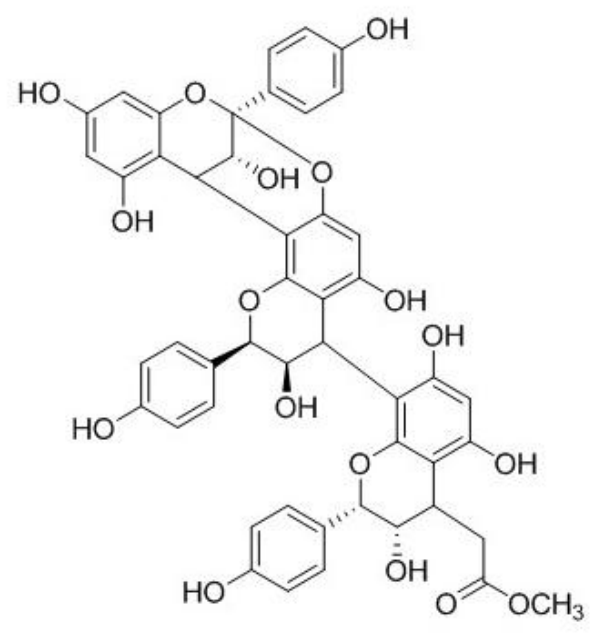

Selligueain B

Proanthocyanidins are a class of oligomeric or polymeric flavan-3-ol units found in many plants and foods. They are known to possess numerous bioactivities, including antioxidant, antimicrobial, hypolipidemic and cardioprotective properties [4-8]. We have shown that mangosteen proanthocyanidins and a novel thio-containing conjugate derived from this polymeric material are powerful antioxidants [9,10]. Additionally, several thiolytic products of proanthocyanidins were revealed to be potential candidates for safe neuroprotective agents $[11,12]$. It is very interesting that the nonphenolic part of the molecule enhanced the capability to penetrate biological membranes and the 
layers of the skin $[12,13]$. Reported herein are our results on the PSFs profile and the peroxyl radical scavenging capacity of the various identified components. The thiolytic products were also purified and their antioxidant activities were tested in order to explore some promising applications of these compounds.

\section{Results and Discussion}

Typical solvent extraction and fractionation on Sephadex LH- 20 gave $3.93 \mathrm{~g}$ of proanthocyanidin mixture from $200 \mathrm{~g}$ of fresh rhizomes of $S$. feei, corresponding to a $1.96 \%$ yield based on fresh weight. The proanthocyanidins content is reasonable compared to other food products, except for cocoa and grape seed, whose proanthocyanidin contents are unusually rather high (more than 10\% of dry weight) $[14,15]$.

Proanthocyanidins from the rhizomes of $S$. feei (PSFs) were revealed to be oligomeric proanthocyanidins (OPCs) according to the ${ }^{1} \mathrm{H}-\mathrm{NMR}$ spectrum in $\mathrm{CD}_{3} \mathrm{OD}$ (Figure 2). The mean degree of polymerization $(\mathrm{mDP})$ of the $S$. feei OPCs was calculated to be 2.6 by integrating the A-ring proton signals between 5.8 and $6.5 \mathrm{ppm}$ and comparing them to the intensity of the $\mathrm{H} 4$ signals of the terminal units between 2.4 and 3.0 ppm based on the following equation [16]:

$$
\mathrm{mDP}=2 \times \frac{(\mathrm{H} 6+\mathrm{H} 8) \text { signal area }}{(\mathrm{H} 4) \text { signal area }}-1
$$

Figure 2. Room temperature $300 \mathrm{MHz}{ }^{1} \mathrm{H}-\mathrm{NMR}$ spectrum of proanthocyanidins from the rhizomes of Selliguea feei (solvent, $\mathrm{CD}_{3} \mathrm{OD}$ ).

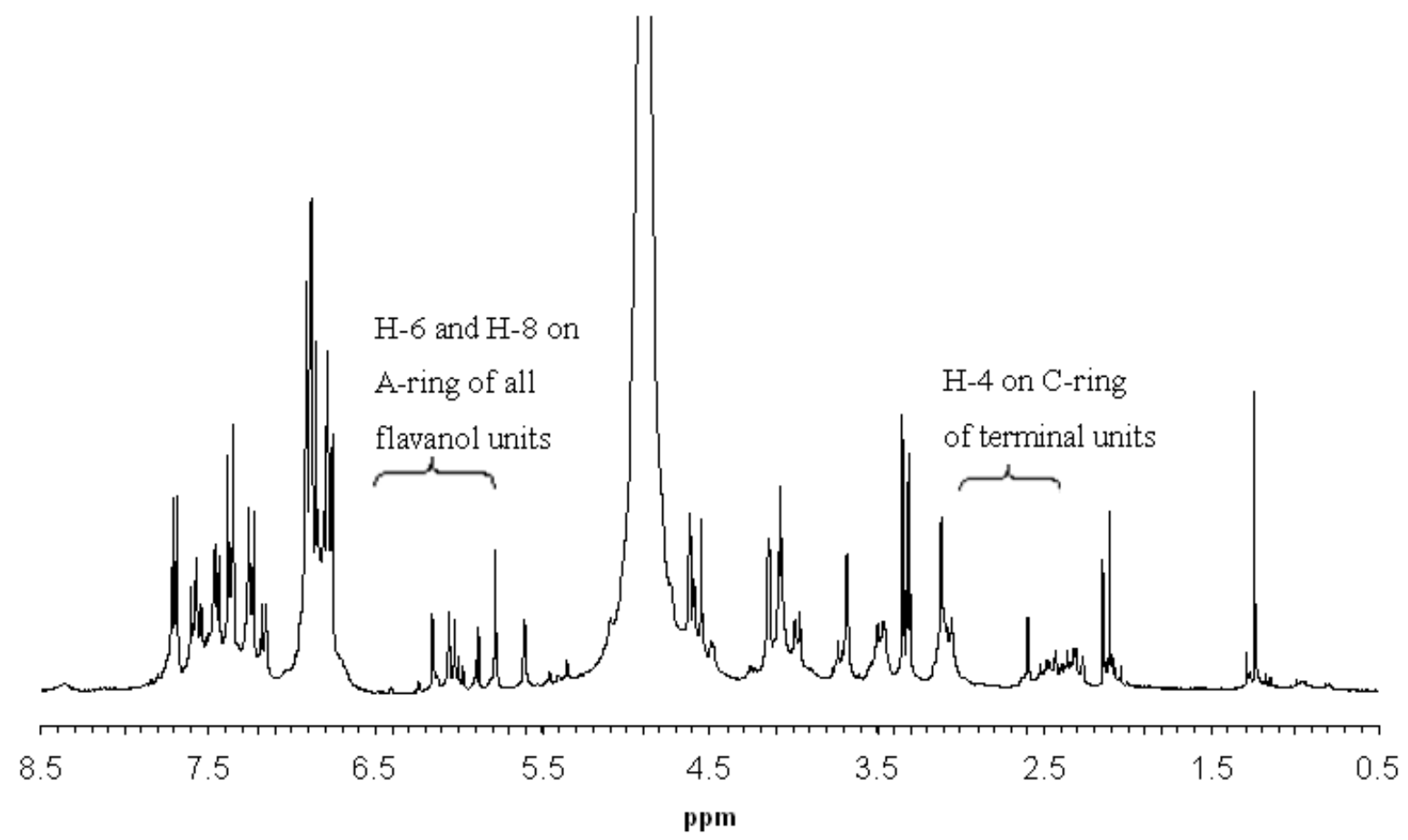

The ${ }^{13} \mathrm{C}$-NMR spectrum (Figure 3 ) of the PSFs in $\mathrm{CD}_{3} \mathrm{OD}$ shows characteristic propelargonidin peaks. PSFs are mostly composed of propelargonidin (afzelechin/epiafzelechin) units in light of the absence of a clear signal at $145 \mathrm{ppm}$ and $146 \mathrm{ppm}$, where procyanidin units and prodelphinidin units 
generally show a typical resonance, respectively [17]. The structural diversity of the linkages (A and B type) and stereochemistry is apparent from the spectrum. Specifically, the C5, C7, C8a and C4'carbons of propelargonidin appear at 160 to $150 \mathrm{ppm}$. The cluster of peaks around $131 \mathrm{ppm}$ belongs to $\mathrm{Cl}^{\prime}$ ' and the peak at 116 ppm is assigned to C3' and C5'. The peaks between 110 and 90 ppm is assigned to C8, C6, C6', and C2'. The region between 70 and $90 \mathrm{ppm}$ is sensitive to the stereochemistry of the $\mathrm{C}$ ring. The ratio of the 2,3-cis to 2,3-trans isomers could be determined through the distinct differences in their respective $\mathrm{C} 2$ chemical shifts, since $\mathrm{C} 2$ gives a resonance line at $76 \mathrm{ppm}$ for the $c i s$ and at $84 \mathrm{ppm}$ for the trans form. The latter is clearly visible in the spectrum, indicating that both stereoisomers (afzelechin/epiafzelechin) are present here. The $\mathrm{C} 3 \mathrm{~s}$ in terminal units generally have their chemical shift around $67 \mathrm{ppm}$. The $\mathrm{C} 4$ atoms of the extension units appeared at $37 \mathrm{ppm}$, while the terminal $\mathrm{C} 4$ exhibits multiple lines around $29 \mathrm{ppm} \mathrm{[17].} \mathrm{A} \mathrm{typical} \mathrm{B-type} \mathrm{interflavanyl} \mathrm{linkage} \mathrm{was} \mathrm{indicated} \mathrm{from}$ shift of the $\mathrm{C} 2$ at $78 \mathrm{ppm}$ and an obvious A-type linkage was indicated from the signals at 151-152 ppm due to $\mathrm{C} 5$ and $\mathrm{C} 7$ of the A ring involved in the double linkage. The chemical shift of the ketal carbon (C2) formed as a result of this additional bond observed at $104.7 \mathrm{ppm}$ provided further support for an A-type linkage.

Figure 3. Room temperature $75 \mathrm{MHz}{ }^{13} \mathrm{C}-\mathrm{NMR}$ spectrum of proanthocyanidins from the rhizomes of Selliguea feei (solvent $\mathrm{CD}_{3} \mathrm{OD}$ ).
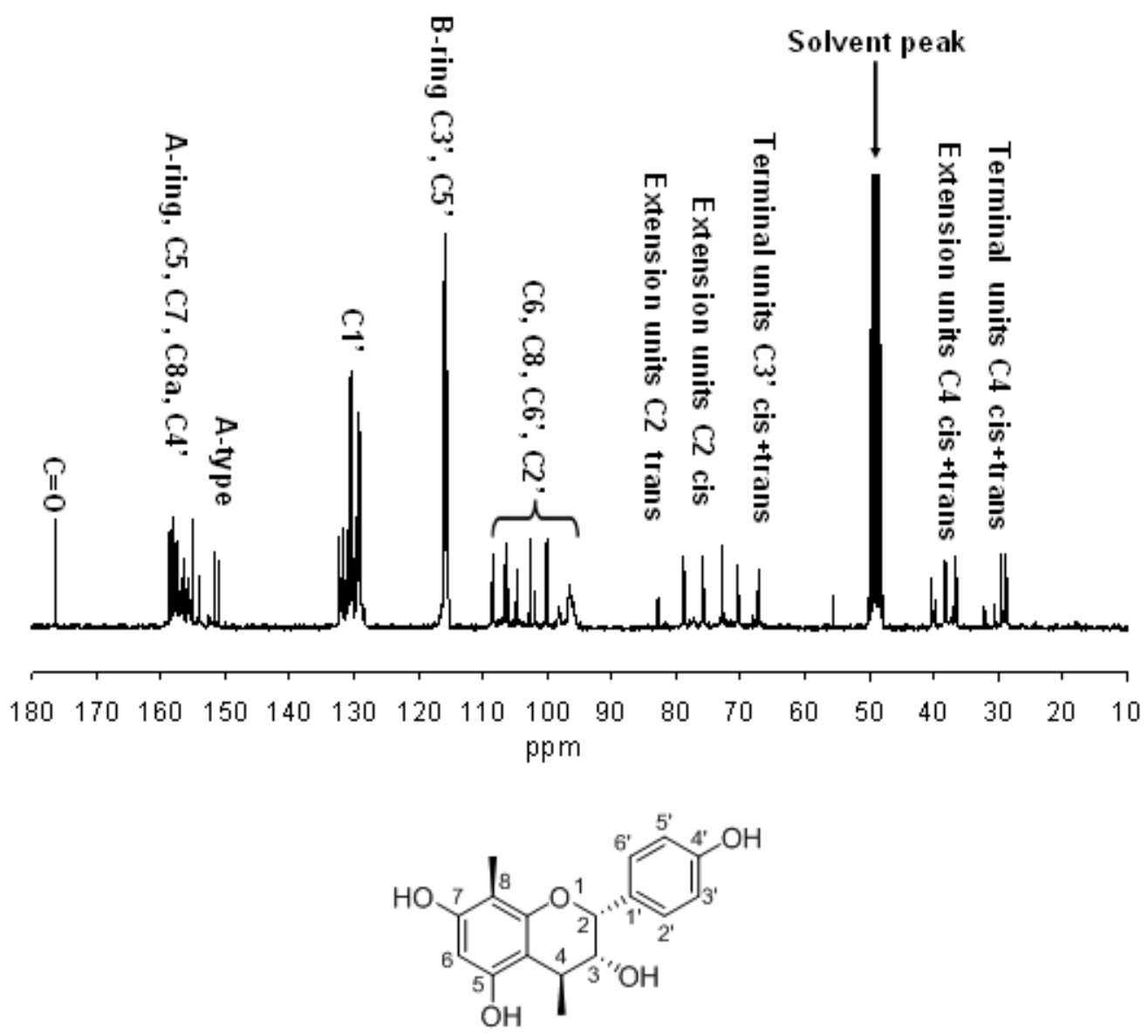

In order to determine the FSPs profile, further characterization was performed by means of ESI/MS and MALDI-TOF MS spectrometry. Analysis was performed in the negative ion mode as proanthocyanidin molecules are better detected by this method than in the positive ion mode. Figure 4 
shows the ESI-MS spectrum of the FSPs. Consistent with the NMR spectra, abundant ions were observed from $m / z 331$ to 873, corresponding to the molecular masses of propelargonidins with DP 1-3. The peak at $m / z=815$ is due to selligueain A (trimer) while the peak at $m / z=889$ is from selligueain

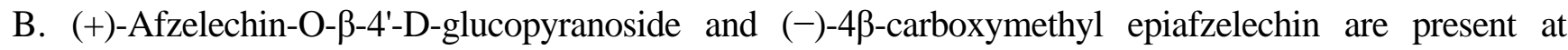
$\mathrm{m} / \mathrm{z}=473$ and $\mathrm{m} / \mathrm{z}=331$, respectively. The peak at $\mathrm{m} / \mathrm{z}=603$ may be due to A-type carboxymethyl propelargonidin dimer, while $\mathrm{m} / z=541$ can be from fragmentation of selligueain $\mathrm{A}(\mathrm{m} / \mathrm{z}$ 815) after quinone-methide $(\mathrm{QM})$ cleavage of the interflavanyl bond, as shown in Figure 4. In addition, there is another proanthocyanidin trimer present, as seen from the peak at $m / z=873$. It corresponds to the most abundant ion. In fact, higher molecular weight proanthocyanidins are more difficult to detect with a good precision in the same spectra as their singly charged ions are often observed with a weak intensity, so this ion should correspond to a proanthocyanidin with high ratio. According to the ${ }^{13} \mathrm{C}$ NMR spectra of PSFs, we proposed the structure of this trimer to be demethylated selligueain $\mathrm{B}$, a rare trimer only found previously in another fern [18]. After purification on silica gel, this trimer exhibits spectral (UV, IR, ${ }^{1} \mathrm{H}-\mathrm{NMR},{ }^{13} \mathrm{C}-\mathrm{NMR}$, ESI-MS) data comparable to published values [18]. There are almost no proanthocyanidin signals after $m / z$ 900. MALDI-TOF MS results also indicated that there is no obvious signal corresponding to higher molecule weight polymers, which agrees with the ${ }^{1} \mathrm{H}-$ and ${ }^{13} \mathrm{C}-\mathrm{NMR}$ spectra.

Figure 4. ESI/MS spectra of proanthocyanidins from the rhizomes of Selliguea feei recorded in the negative ion mode and the possible fragmentation pathway for selligueain A.

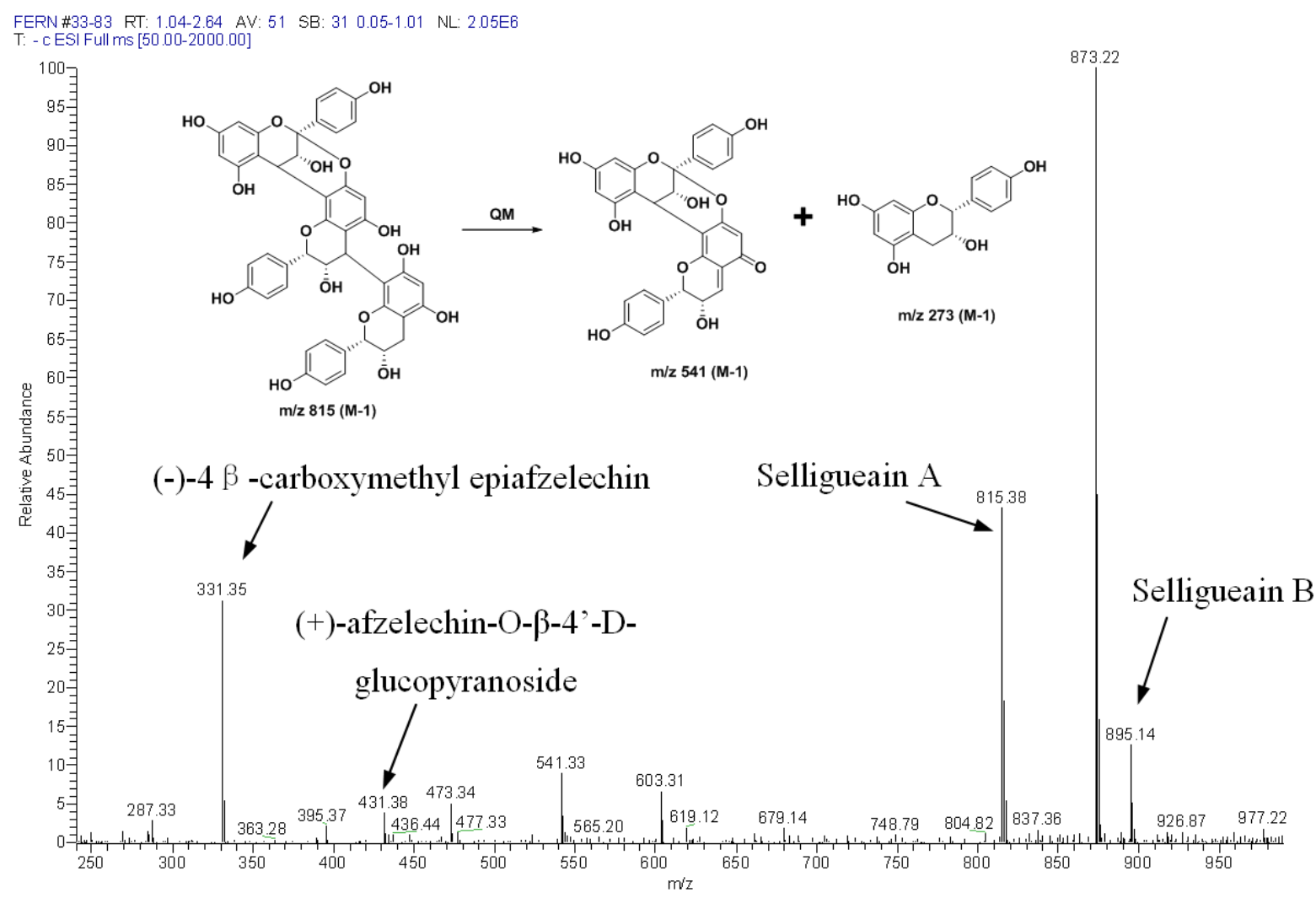

Thiolysis of the demethylated selligueain B with methyl thioglycolate produced a novel monomer 1 and thioether $\mathbf{2}$. The molecular weight of the thioether $\mathbf{2}$ is determined from ESI-MS spectroscopy as 647 from the anionic mode MS. This thiolytic product is still an A-type propelargonidin dimer since 
only the B-type interflavanyl bond is readily cleaved under these acidic conditions $[19,20]$. When the thiolysis was carried out in methanol the desired terminal unit was not obtained. Instead, the methyl ester 1 was isolated as a new compound. Apparently under the acidic methanolic conditions, the depolymerization and esterification occurred in one pot to afford to observed product. The unesterified product can be generated via depolymerization in none-alcoholic media such as 1,4-dioxane.

The peroxyl radical scavenging capacity of selligueain A, the demethylated selligueain B and the thiolytic products was determined using an oxygen radical absorbance capacity (ORAC) assay in order to investigate the mechanism. The kinetic curves from the ORAC assay show a dose dependent response with a clear lag phase compared to a Trolox standard. The net area under the curve has an excellent linear relationship with the concentration of proanthocyanidins and the thiolytic products (Figure 5). Selligueain A and the demethylated selligueain B, the novel monomer $\mathbf{1}$ and propelargonidin dimer 2 are potent peroxyl radical scavengers as evidenced by the high oxygen radical scavenging capacity values of $1.18 \times 10^{4}, 1.16 \times 10^{4}, 0.95 \times 10^{4}$ and $1.29 \times 10^{4} \mu \mathrm{mol} \mathrm{TE} / \mathrm{g}$, respectively. The ORAC values of mangosteen oligomeric proanthocyanidins and commercially available grape seed proanthocyanidins were $1.7 \times 10^{4}, 1.0 \times 10^{4} \mu \mathrm{mol} \mathrm{TE} / \mathrm{g}$, respectively [9]. Therefore, these components derived from the rhizomes of Selliguea feei may be promising antioxidants.

Figure 5. Linear relationships of compounds from Selliguea feei versus area under the curve.
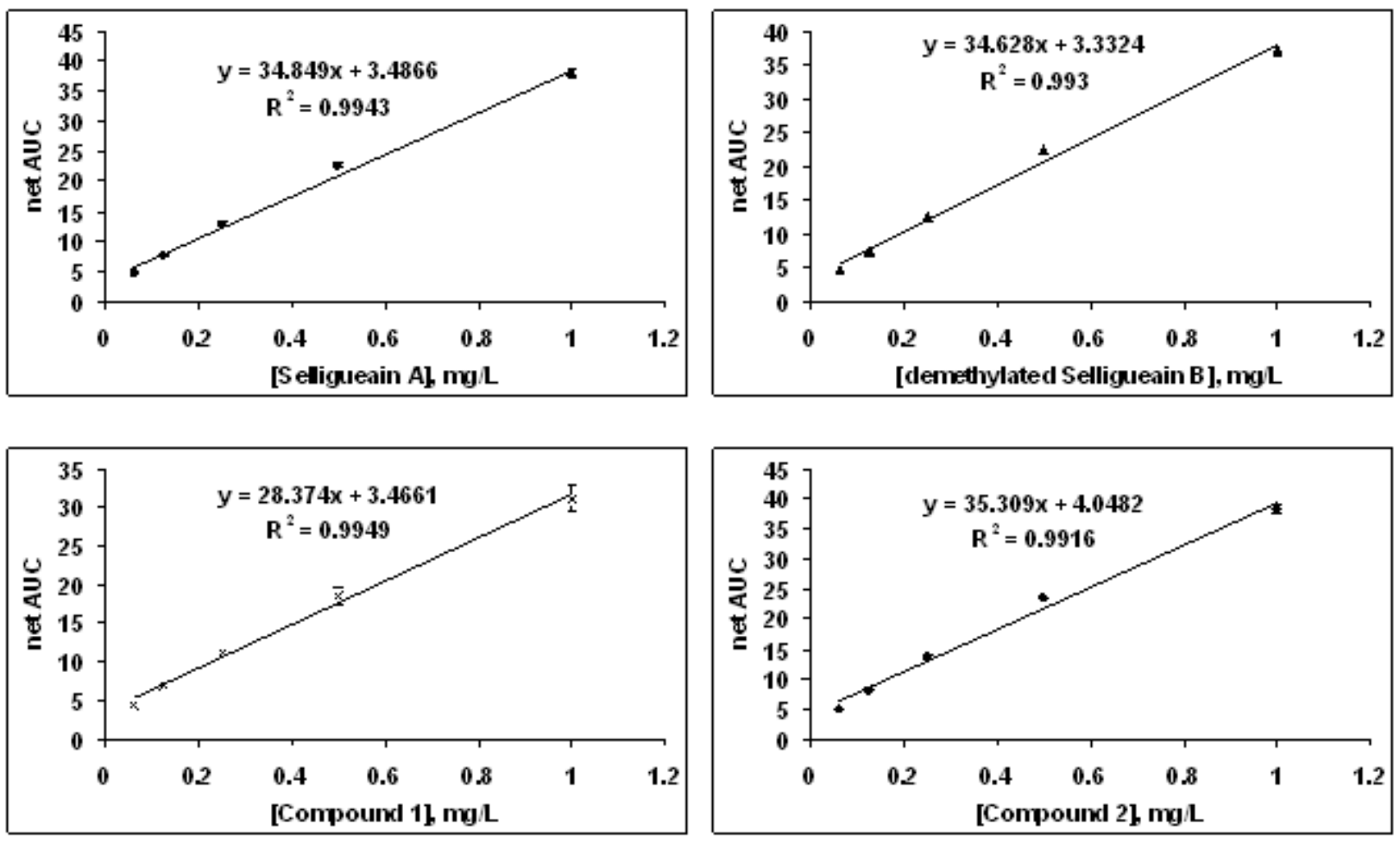

Proanthocyanidins isolated from different plants show various degree of polymerizations and characteristic monomeric units. Besides the $S$. feei proanthocyanidins, red kidney bean, strawberry and cinnamon are typical foods containing propelargonidin units [19,21,22]. Proanthocyanidins in red kidney bean have been found to contain the highest proportion of (epi)afzelechin (14.6\%) among 88 different kinds of foods. Propelargonidins contribute about $8.2-11.6 \%$ of the proanthocyanidins in pinto bean, small red bean, and red kidney bean. The principal proanthocyanidins in these foods are, 
however, procyanidins [19]. Proanthocyanidins only consisting of afzelechin/epiafzelechin units are rare. A highly sweet proanthocyanidin trimer from the rhizomes of $S$. feei, selligueain A, has been reported to be anti-inflammatory and analgesic, which could be used to treat rheumatism [2]. As unusual secondary metabolites, PSFs and their derivatives warrant further investigation regarding their therapeutic potential and use in chronic disease prevention or as food additives.

\section{Experimental}

\subsection{Instruments}

${ }^{1} \mathrm{H}$ and ${ }^{13} \mathrm{C}$-NMR spectra were recorded in deuterated methanol for proanthocyanidins and in deuterated acetone for thiolytic products with a Bruker AC300 spectrometer (Karlsruhe, Germany) operating at 300 and $75 \mathrm{MHz}$, respectively. The electron spray ionization mass spectra (ESI-MS) were obtained from a Finnigan/MAT LCQ ion trap mass spectrometer (San Jose, CA, USA). The heated capillary and voltage were maintained at $250{ }^{\circ} \mathrm{C}$ and $4.5 \mathrm{kV}$, respectively. The full-scan mass spectra from $\mathrm{m} / \mathrm{z} 50$ to 2000 were recorded. The proanthocyanidins from the rhizomes of $S$. feei (PSFs) were dissolved in methanol and the solution was introduced into the ion spray source with a syringe (100 $\mathrm{uL})$. High resolution mass spectra (HRMS) were obtained on a Finnigan (MAT 95XL-T) high resolution $(60,000)$, 5KV Double Focusing Reversed Nier-Johnson Geometry Mass Spectrometer.

\subsection{Reagents}

All solvents used were of reagent grade unless otherwise specified. The rhizomes of $S$. feei were purchased from Indonesia and kept at $-20{ }^{\circ} \mathrm{C}$ before use. Sephadex ${ }^{\mathrm{TM}} \mathrm{LH}-20$ was purchased from GE Healthcare Bi-Sciences AB (Uppsala, Sweden). Methyl thioglycolate, 2,2'-azobis(2-methylpropionamidine) dihydrochloride (AAPH), and Trolox were purchased from Sigma-Aldrich Chemical Company (St. Louis, MO, USA).

\subsection{Extraction and Purification of Proanthocyanidins from the Rhizomes of $\mathrm{S}$. feei}

The rhizomes of S. feei (200 g) were meshed and Soxhlet defatted with hexane $(500 \mathrm{~mL} \times 2)$. Condensed tannins were subsequently extracted from the residue by a mixture of acetone/water (7:3, $1,000 \mathrm{~mL}$ ) for $4 \mathrm{~h}$, according to a classical extraction method for proanthocyanidins [9], and then the mixture was filtered. The extraction was repeated two times and the filtrates were pooled. The acetone in the filtrate was evaporated to yield a slurry mass, which was centrifuged at 3,000 $\mathrm{g}$ for $15 \mathrm{~min}$. The supernatant was collected and liquid-liquid extracted with dichloromethane $(3 \times 200 \mathrm{~mL})$ to further remove other lipophilic compounds. The water phase was collected and concentrated to $40 \mathrm{~mL}$. The crude proanthocyanidin fraction $(20 \mathrm{~mL})$ was filtered through a 45 micron porosity filter (Minisart) and then loaded on a Sephadex LH-20 column (100 grams of LH-20, equilibrated with MeOH/water (1:1) for $4 \mathrm{~h}$ ). The column was washed with $\mathrm{MeOH} /$ water (1:1) until the eluent turned colorless. The adsorbed proanthocyanidins were then eluted with aqueous acetone $(70 \%, 500 \mathrm{~mL})$. The acetone was removed on a rotary evaporator at $40{ }^{\circ} \mathrm{C}$ and the resulting residue freeze-dried to give a light brown powder (3.93 g overall yield from the $200 \mathrm{~g}$ fresh the rhizomes of $\mathrm{S}$. feei $)$. A portion $(2.0 \mathrm{~g}) \mathrm{of}$ PSFs was applied over sequential silica gel columns, eluting with dichloromethane-methanol $(3: 1)$ and 
acetone-dichloromethane-hexane (5:1:1), respectively, to afford demethylated selligueain B (603 mg). This trimer was identified by comparison of its spectral data (UV, IR, ${ }^{1} \mathrm{H}$ and ${ }^{13} \mathrm{C}-\mathrm{NMR}$ ) with published data [18]. In order to test the antioxidant activity, selligueain A was also purified following a previously reported method [1].

\subsection{Thiolysis}

In a flask $(100 \mathrm{~mL})$, the purified demethylated selligueain B $(300 \mathrm{mg})$ was mixed with methanol $(30 \mathrm{~mL})$, hydrochloric acid $(36 \%, 0.3 \mathrm{~mL})$, and methyl thioglycolate $(0.3 \mathrm{~mL})$. The mixture was heated with stirring at $65^{\circ} \mathrm{C}$ for $12 \mathrm{~h}$ (Scheme 1). The filtrate was neutralized with $0.1 \mathrm{M} \mathrm{NaHCO}_{3}$ to $\mathrm{pH} 6.5$ before it was extracted with ethyl acetate $(4 \times 50 \mathrm{~mL})$. The combined organic fraction was dried over anhydrous sodium sulphate. Evaporation of the ethyl acetate gave a dark brown residue, which was applied to sequential silica gel columns, eluting with ethyl acetate-hexane (2:1) and dichloromethanemethanol (9:1), respectively, to afford the methyl ester of terminal unit 1 (44 mg) as a light brown solid and a thioether $2(113 \mathrm{mg})$ as a light yellow solid.

Scheme 1. Thiolysis of the demethylated selligueain B.
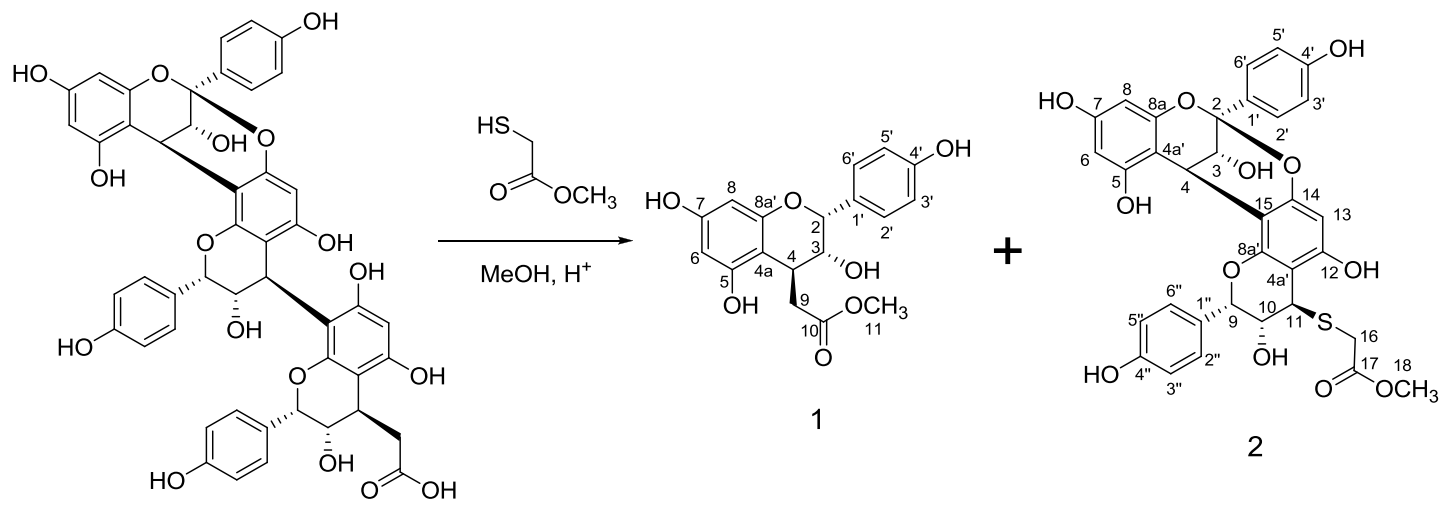

Methyl 2-((2R,3R,4S)-3,5,7-trihydroxy-2-(4-hydroxyphenyl)chroman-4-yl)acetate $\quad(\mathbf{1}) . \quad{ }^{1} \mathrm{H}-\mathrm{NMR}$ (acetone- $\left.\mathrm{d}_{6}\right): \delta=7.39$ [d, $\left.J=8.5 \mathrm{~Hz}, 2 \mathrm{H}, \mathrm{C}\left(2^{\prime}, 6^{\prime}\right)-\mathrm{H}\right], 7.37\left[\mathrm{~d}, J=8.5 \mathrm{~Hz}, 2 \mathrm{H}, \mathrm{C}\left(3^{\prime}, 5^{\prime}\right)-\mathrm{H}\right], 6.04[\mathrm{~d}$, $J=2.3,1 \mathrm{H}, \mathrm{C}(6)-\mathrm{H}], 5.94[\mathrm{~d}, J=2.3 \mathrm{~Hz}, 1 \mathrm{H}, \mathrm{C}(8)-\mathrm{H}], 4.96[\mathrm{~s}, 1 \mathrm{H}, \mathrm{C}(2)-\mathrm{H}], 3.94[\mathrm{~d}, J=4.7 \mathrm{~Hz}, 1 \mathrm{H}$, $\mathrm{C}(4)-\mathrm{H}], 3.74[\mathrm{~d}, J=5.7 \mathrm{~Hz}, 1 \mathrm{H}, \mathrm{C}(3)-\mathrm{H}], 3.67$ [s, 3H, C(11)-H], 3.06 and 2.52 [two dd, $\left.J_{1}=12.5 \mathrm{~Hz}, J_{2}=3.6 \mathrm{~Hz}, 2 \mathrm{H}, \mathrm{C}(9)-\mathrm{H}\right] .{ }^{13} \mathrm{C}\{1 \mathrm{H}\}-\mathrm{NMR}$ (acetone-d $\left.{ }_{6}\right): \delta=172.2(\mathrm{C}-10), 157.0(\mathrm{C}-5)$, 156.9 (C-7), 156.7 (C-8a), 156.0(C-4), 130.3(C-1'), 128.2 (C-2' and C-6'), 114.6 (C-3' and C-5'), 101.5 (C-4a), 95.5 (C-6), 94.9 (C-8), 74.4 (C-2), 69.1 (C-3), 50.7 (C-11), 38.2 (C-4), 35.3 (C-9). MS (ESI, -c): 345 [M-H] ${ }^{-}$IR (KBr): 3412, 2954, 1715, 1616, 1518, 1468, 1365, 1238, 1172, 1149, 1130, 1050, $1025,818,795 \mathrm{~cm}^{-1}$.

$4 \beta$-(Carboxymethyl)sulphanyl-epiafzelechin- $(2 \beta \rightarrow O \rightarrow 7,4 \beta \rightarrow 8)$-epiafzelechin methyl ester (2). ${ }^{1} \mathrm{H}-\mathrm{NMR}$ (acetone- $\mathrm{d}_{6}$ ): $\delta=7.70$ [s, 1H, (C2')-H], 7.67 [s, 1H, (C6')-H], 7.57 [s, 1H, (C2")-H], 7.54 [s, 1H, (C6")-H], 6.94 [s, 1H, (C3')-H], 6.91 [s, 1H, (C3')-H], 6.89 [s, 1H, (C3")-H], 6.86 [s, 1H, (C5")-H], 6.17 [s, 1H, (C13)-H], 6.09 [d, $J=2.3,1 \mathrm{H},(\mathrm{C}-6)-\mathrm{H}], 6.99$ [d, $J=2.3,1 \mathrm{H},(\mathrm{C}-8)-\mathrm{H}], 5.36$ [s, 1H, C(9)-H], 4.37 [d, J = 3.5, 1H, (C-4)-H], 4.29 [s, 1H, (C-10)-H], 4.17 [s, 1H, (C-3)-H], 4.14 [s, 1H, (C-11)-H]; 3.74 [m, 4H, (C-18, C-19)-H]. ${ }^{13} \mathrm{C}\left\{{ }^{1} \mathrm{H}\right\}-N M R$ (acetone-d $\left.{ }_{6}\right): \mathrm{d}=173.4$ (C-16), 159.2 (C-4'), 158.6 (C-4"), 
157.9 (C-12), 157.6 (C-7), 154.6 (C-5), 154.7 (C-14), 152.3 (C-8a, C-8a'), 132.1 (C-1", C-1'), 131.3 (C-2", C-6"), 130.2 (C-2'), 130.0 (C-6'), 116.5 (C-3", 5"), 115.9 (C-3',5'), 107.7 (C-8), 104.3 (C-4a), 102.0 (C-4a'), 100.7 (C-2), 98.8 (C-6), 98.2 (C-13), 96.9 (C-8), 78.1 (C-9), 71.1 (C-10), 68.0 (C-3), 53.7 (C-18), 45.1 (C-11), 34.9 (C-16), 27.8 (C-4). MS (ESI, -c): 647 [M-H] $]^{-}$IR (KBr): 3391, 2956, $1715,1615,1518,1474,1449,1378,1307,1230,1174,1143,1120,1009,966,899,880,835,781$, $747 \mathrm{~cm}^{-1}$.

\subsection{Antioxidant Capacity Analysis}

The oxygen radical absorbance capacity (ORAC) is the excellent method combining both degree of inhibition and inhibition time into a single quantity [23]. Oxygen radical absorbance capacity $\left(\mathrm{ORAC}_{\mathrm{FL}}\right)$ assays were carried out on a Synergy HT fluorescent microplate reader with an excitation wavelength of $485 \mathrm{~nm}$ and an emission wavelength of $525 \mathrm{~nm}$ (Bio-tek Instruments Inc., Winooski, VT, USA). The temperature of the incubator was set at $37{ }^{\circ} \mathrm{C}$. The procedures were based on the modified ORAC $\mathrm{FL}_{\mathrm{FL}}$ method [23]. All assays were carried out in triplicate and the data are expressed as micromoles of Trolox equivalents per gram $(\mu \mathrm{mol} \mathrm{TE} / \mathrm{g})$.

\section{Conclusions}

In summary, we have shown that the rhizomes of Selliguea feei are a good source of oligomeric proanthocyanidins consisting of afzelechin/epiafzelechin units with A-type and B-type interflavanyl linkages. Two novel thiolytic products and two propelargonidin trimers from the rhizomes of Selliguea feei are potent peroxyl radical scavengers as evidenced by the high antioxidant capacity. The chemistry behind these compounds may warrant further study for exploring potential therapeutic applications or as food additives.

\section{Acknowledgments}

Dejian Huang thanks the Ministry of Education of Singapore for financial support (R-143-000-299112). This work was supported by the Natural Science Foundation of Fujian Province, China (Grant No. 2012J05056).

\section{References}

1. Baek, N.I.; Chung, M.S.; Shamon, L.; Kardono, L.B.; Tsauri, S.; Padmawinata, K.; Pezzuto, J.M.; Soejarto, D.D.; Kinghorn, A.D. Selligueain-A, A novel highly sweet proanthocyanidin from the rhizomes of Selliguea feei. J. Nat. Prod. 1993, 56, 1532-1538.

2. Chang, E.J.; Lee, W.J.; Cho, S.H.; Choi, S.W. Proliferative effects of flavan-3-ols and propelargonidins from rhizomes of Drynaria fortunei on MCF-7 and osteoblastic cells. Arch. Pharm. Res. 2003, 26, 620-630.

3. Baek, N.I.; Chung, M.S.; Shamon, L.; Kardono, L.B.; Tsauri, S.; Padmawinata, K.; Pezzuto, J.M.; Soejarto, D.D.; Kinghorn, A.D. Flavonoids and a proanthocyanidin from rhizomes of Selliguea feei. Phytochemistry 2004, 36, 513-518. 
4. Xu, Z.; Du, P.; Meiser, P.; Jacob, C. Proanthocyanidins: oligomeric structures with unique biochemical properties and great therapeutic promise. Nat. Prod. Commun. 2012, 7, 381-388.

5. Diouf, P.N.; Stevanovic, T.; Cloutier, A. Study on chemical composition, antioxidant and anti-inflammatory activities of hot water extract from Picea mariana bark and its proanthocyanidin-rich fractions. Food Chem. 2009, 113, 897-902.

6. Bladé, C.; Arola, L.; Salvadó, M.J. Hypolipidemic effects of proanthocyanidins and their underlying biochemical and molecular mechanisms. Mol. Nutr. Food Res. 2010, 54, 37-59.

7. Guler, A.; Sahin, M.A.; Yucel, O.; Yokusoglu, M.; Gamsizkan, M.; Ozal, E.; Demirkilic, U.; Arslan, M. Proanthocyanidin prevents myocardial ischemic injury in adult rats. Med. Sci. Monit. 2011, 17, 326-331.

8. Arola-Arnal, A.; Blade, C. Proanthocyanidins modulate microRNA expression in human HepG2 cells. PLoS One 2011, 6, e25982.

9. $\mathrm{Fu}$, C.; Loo, A.E.; Chia, F.P.; Huang, D. Oligomeric proanthocyanidins from mangosteen pericarps. J. Agric. Food Chem. 2007, 55, 7689-7694.

10. Chen, W.; Fu, C.; Qin, Y.; Huang, D. One-pot depolymerizative extraction of proanthocyanidins from mangosteen pericarps. Food Chem. 2007, 114, 874-880.

11. Torres, J.L.; Lozano, C.; Julià, L.; Sánchez-Baeza, F.J.; Anglada, J.M.; Centelles, J.J.; Cascante, M. Cysteinyl-flavan-3-ol conjugates from grape procyanidins. Antioxidant and antiproliferative properties. Bioorg. Med. Chem. 2002, 10, 2497-2509.

12. Mitjans, M.; Martínez, V.; Campo J.D.; Abajo, C.; Lozano, C.; Torres, J.L.; Vinardell, M.P. Novel epicatechin derivatives with antioxidant activity modulate interleukin-1beta release in lipopolysaccharide-stimulated human blood. Bioorg. Med. Chem. Lett. 2004, 14, 5031-5034.

13. Jiménez, A.; Selga, A.; Torres, J.L.; Julià, L. Reducing activity of polyphenols with stable radicals of the TTM series. Electron transfer versus $\mathrm{H}$-abstraction reactions in flavan-3-ols. Org. Lett. 2004, 6, 4583-4586.

14. Gu, L.; House, S.E.; Wu, X.; Ou, B.; Prior, R.L. Procyanidin and catechin contents and antioxidant capacity of cocoa and chocolate products. J. Agric. Food Chem. 2006, 54, 4057-4061.

15. Gu, L.; Kelm, M.A.; Hammerstone, J.F.; Beecher, G.; Holden, J.; Haytowitz, D.; Gebhardt, S.; Prior, R.L. Concentrations of proanthocyanidins in common foods and estimations of normal consumption. J. Nutr. 2004, 134, 613-617.

16. Guyot, S.; Le Guerneve, C.; Marnet, N.; Drilleau, J.F. Methods for determining the degree of polymerization of condensed tannins: A new $1 \mathrm{H}$ NMR procedure applied to cider apple procyanidins. In Plant Polyphenols 2: Chemistry, Biology, Pharmacology, Ecology; Gross, C.G., Yoshida, T., Eds.; Kluwer Academic/Plenum Publishers, New York, NY, USA, 1999; pp. 211-222.

17. Czochanska, Z.; Foo, L.Y.; Newman, R.H.; Porter, L.J. Polymeric proanthocyanidins. Stereochemistry, structural units and molecular weight. J. Chem. Soc. Perkin. Trans. 1980, 1, 2278-2286.

18. Wada, H.; Daidouji, K.; Fuchino, H.; Endo, J.; Nakamura, T.; Tanaka, N.; Murakami, T.; Saiki, Y. Chemical and chemotaxonomical studies of ferns .lxxx. Proanthocyanidins of Arachnoides sporadosora Nakaike and A. exilis Ching. Chem. Pharm. Bull. 2004, 39, 55-59. 
19. Gu, L.; Kelm, M.A.; Hammerstone, J.F.; Beecher, G.; Holden, J.; Haytowitz, D.; Prior, R.L. Screening of foods containing proanthocyanidins and their structural characterization using LC/MS/MS and thiolytic degradation. J. Agric. Food Chem. 2003, 51, 7513-7521.

20. Fu, C.L.; Chen, W.; Quek, Y.L.; Ni, R.Y.; Ghani, A.B.A.; Leong, W.W.Y.; Zeng, H.Q.; Huang, D.J. Sustainability from agricultural waste- chiral ligands from oligomeric proanthocyanidins via acid-mediated depolymerization. Tetrahedron Lett. 2010, 51, 6322-6324.

21. Buendía, B.; Gil, M.I.; Tudela, J.A.; Gady, A.L.; Medina, J.J.; Soria, C.; López, J.M.; Tomás-Barberán, F.A. HPLC-MS analysis of proanthocyanidin oligomers and other phenolics in 15 strawberry cultivars. J. Agric. Food Chem. 2010, 58, 3916-3926.

22. Mateos-Martín, M.L.; Fuguet, E.; Quero, C.; Pérez-Jiménez, J.; Torres, J.L. New identification of proanthocyanidins in cinnamon (Cinnamomum zeylanicum L.) using MALDI-TOF/TOF mass spectrometry. Anal. Bioanal. Chem. 2012, 402, 1327-1336.

23. Huang, D.; Ou, B.; Hampsch-Woodill, M.; Flanagan, J.A.; Prior, R.L. High-throughput assay of oxygen radical absorbance capacity (ORAC) using a multichannel liquid handling system coupled with a microplate fluorescence reader in 96-well format. J. Agric. Food Chem. 2002, 50, 4437-4444.

Sample Availability: Samples of the compounds are available from the authors.

(C) 2013 by the authors; licensee MDPI, Basel, Switzerland. This article is an open access article distributed under the terms and conditions of the Creative Commons Attribution license (http://creativecommons.org/licenses/by/3.0/). 